\title{
Nanosecond Transient Absorption Spectroscopy of a Ru Polypyridine Phenothiazine Dyad
}

Gilbert K. Kosgei, ${ }^{1 *}$ Maksim Y. Livshits, ${ }^{2}$ Theodore R. Canterbury, ${ }^{1}$ Jeffery J. Rack, ${ }^{2 *}$ and Karen J. Brewer ${ }^{1}$

${ }^{1}$ Department of Chemistry, Virginia Tech, Blacksburg, VA 24061-0212, United States

${ }^{2}$ Department of Chemistry and Chemical Biology, University of New Mexico, Albuquerque, NM 87131-0001

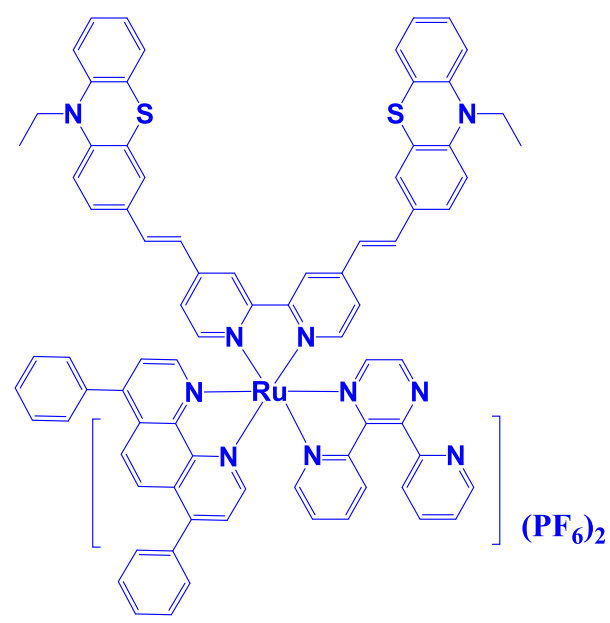

\section{Abstract}

A bipyridine phenothiazine ligand [(PTZEtv 2 bpy $)$ and metal complexes $\left[\mathrm{Ru}\left(\mathrm{Ph}_{2} \mathrm{phen}\right)_{3}\right]^{2+}(\mathbf{1})$, $\left[\left(\mathrm{Ph}_{2} \text { phen }\right)_{2} \mathrm{Ru}\left(\mathrm{PTZEtv}_{2} \text { bpy }\right)\right]^{2+} \quad$ (2), and $\left[\left(\mathrm{PTZEtv}_{2} \text { bpy }\right)\left(\mathrm{Ph}_{2} \text { phen }\right) \mathrm{Ru}(\mathrm{dpp})\right]^{2+}$ (3) were synthesized and characterized, where $\mathrm{Ph}_{2}$ phen is 4,7-diphenyl-1,10-phenanthroline, dpp is 2,3bis(2-pyridyl)pyrazine and PTZEtv ${ }_{2}$ bpy is 4,4' ethylene bridged phenothiazine 2,2'bipyridine. The reduction potentials of PTZEtv ${ }_{2}$ bpy, $\mathbf{1}, \mathbf{2}$, and $\mathbf{3}$ were determined by cyclic and square wave voltammetric methods. The absorbance and emission spectra of complexes $\mathbf{2}$ and $\mathbf{3}$ yield intense, visible Metal-to-Ligand Charge Transfer (MLCT) transitions. The nanosecond transient absorption data indicate formation of both the ${ }^{3}$ MLCT state and a ligand localized ${ }^{3} \mathrm{PTZ}$ state.

Keywords: RUTHENIUM, POLYPYRIDENE, PHENOTHIAZINE, TRANSIENT ABSORPTION. 


\section{Introduction}

Phenothiazine moieties have previously been attached to ancillary ligands of bipyridines, terpyridine and phenanthroline via a non-conjugated or a pi-conjugated spacer/bridge. ${ }^{[1-4]}$ The ruthenium complexes of such ligands formed Donor-Chromophore-Acceptor assemblies that create separated electron hole pairs for subsequent chemistry. ${ }^{[1,5-11]}$ Such assemblies, either as dyads or triads, have been employed for photoinduced electron / energy transfer ${ }^{[2-6]}$ complexes for solar fuel generation. ${ }^{[12-18]}$ One advantage of phenothiazine is the variable attachment sites to the assembly that may occur through one of the peripheral aromatic rings, the $\mathrm{N}$-atom, or the Satom. ${ }^{[1-4,19]}$ Herein, we report the spectral, electrochemical, and nanosecond transient absorption data of a ruthenium polypyridine dyad comprising phenothiazine with a conjugated linker.

\section{Results and Discussion}

The bipyridine phenothiazine ligand and metal complexes employed in this work are shown in Figure 1. The PTZEtv 2 bpy ligand was prepared via Wittig-Horner coupling of bipyridine di-phosphonate with the aldehyde, PTZEt-CHO ${ }^{[4]}$ The phosphonate was prepared by the Michaelis-Arbuzov reaction with 4,4'-bis(bromomethyl)-2,2'-bipyridine, which was previously formed by bromination of 4,4'-dimethyl-2,2'-bipyridine with N-bromo succinimide (NBS). ${ }^{[20]}$ The aldehyde PTZEt-CHO was prepared by the Vilsmeier-Haack reaction with Nethyl phenothiazine (PTZEt). ${ }^{[4]}$ Similarly, the ruthenium complexes were prepared according to published literature methods. ${ }^{[14]}$ Complex $\mathbf{2}$ was synthesized in a one-pot reaction with $\left[\mathrm{Ru} \text { (benzene) } \mathrm{Cl}_{2}\right]_{2}$ as the starting material followed by sequential addition of PTZEtv ${ }_{2}$ bpy and $\mathrm{Ph}_{2}$ phen ligands, respectively. ${ }^{[5]}$ In contrast, complex 3 was prepared in a multi-step reaction of $\left[\mathrm{Ru} \text { (benzene) } \mathrm{Cl}_{2}\right]_{2}$ and PTZEtv ${ }_{2}$ bpy, $\mathrm{Ph}_{2}$ phen and $\mathrm{dpp}$, in which the intermediates, $\left[\mathrm{Ru}\right.$ (benzene)(PTZEtv 2 bpy)Cl]Cl, and $\left[\mathrm{Ru}\left(\mathrm{PTZEtv}_{2}\right.\right.$ bpy $)\left(\mathrm{Ph}_{2}\right.$ phen $\left.) \mathrm{Cl}_{2}\right]$, were isolated and purified prior to subsequent reaction to produce complex $\mathbf{3}$. Complexes $\mathbf{1}, \mathbf{2}$, and $\mathbf{3}$ were purified by column chromatography. Additional synthetic details are found in the supporting information.

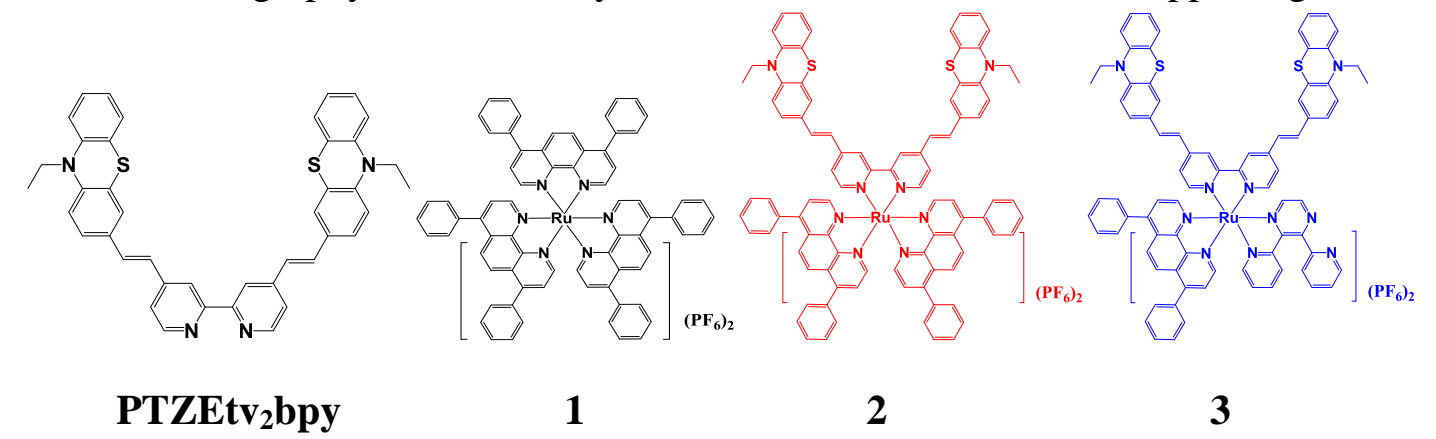

Figure 1. Structures of PTZEtv ${ }_{2}$ bpy ligand, and 1, 2, and $\mathbf{3}$ studied in this work. 1= $\left[\mathrm{Ru}\left(\mathrm{Ph}_{2} \text { phen }\right)_{3}\right]^{2+}, \quad 2=\left[\left(\mathrm{Ph}_{2} \text { phen }\right)_{2} \mathrm{Ru}\left(\mathrm{PTZEtv}_{2} \text { bpy }\right)\right]^{2+}$ and $3=$ $\left[\left(\mathrm{PTZEtv}_{2} \mathrm{bpy}\right)\left(\mathrm{Ph}_{2} \text { phen }\right) \mathrm{Ru}(\mathrm{dpp})\right]^{2+}$.

Electrochemical Properties 
The reduction potentials of PTZEtv ${ }_{2}$ bpy, $\mathbf{1}, \mathbf{2}$, and $\mathbf{3}$ were determined by cyclic and square wave voltammetric methods and are summarized in Table 1 . The voltammograms of uncoordinated PTZEtv ${ }_{2}$ bpy, $\mathbf{2}$, and $\mathbf{3}$ reveal a reversible couple at $\sim+0.75 \mathrm{~V} \mathrm{vs} \mathrm{Ag} / \mathrm{AgCl}$, which is accordingly assigned to oxidation of phenothiazine. This assignment is consistent with literature values of phenothiazine ruthenium polypyridine conjugates. ${ }^{[1,2]}$ These data indicate that the ethyl linkage bridging phenothiazine to ruthenium does not alter the electronic properties of phenothiazine. We observe the $\mathrm{Ru}^{3+/ 2+}$ reduction potential near $+1.25 \mathrm{~V}$ vs Ag/AgCl for $\mathbf{1}, \mathbf{2}$, and $\mathbf{3}$, again indicating that the presence of the phenothiazine does not alter the electronic properties of ruthenium. These data permit the determination of the driving force for ground state electron transfer between reduced $\left(\mathrm{Ph}_{2}\right.$ hen $\bullet$ ) and oxidized PTZ ( $\left.\mathrm{PTZ}^{+} \bullet\right)$ of $0.59 \mathrm{~V}$.

Table 1. Electrochemical properties for PTZEtv 2 bpy, 1, 2, and $\mathbf{3}^{\mathrm{a}}{ }^{\mathrm{a}}$

\begin{tabular}{|c|c|c|}
\hline Ligand/Complex & $\mathbf{E}^{\text {o }}$ in V & assignment \\
\hline \multirow{2}{*}{ PTZEtv $_{2}$ bpy } & +0.75 & $\mathrm{PTZ}^{0 /+}$ \\
& +1.41 & $\mathrm{PTZ}^{1++2 ~} \mathrm{~b}$ \\
\hline \multirow{2}{*}{$\mathbf{2}$} & -1.27 & $\mathrm{Ph}_{2} \mathrm{Phen}^{0 /-}$ \\
& +1.29 & $\mathrm{Ru}^{3+/ 2+}$ \\
\hline \multirow{2}{*}{} & -1.34 & $\mathrm{Ph}_{2} \mathrm{Phen}^{0 /-}$ \\
& +0.75 & $\mathrm{PTZ}^{0 / 1+}$ \\
& +1.20 & $\mathrm{Ru}^{2+/ 3+}$ \\
& +1.44 & $\mathrm{PTZ}^{1+/ 2+\mathrm{b}}$ \\
\hline \multirow{3}{*}{} & -1.01 & $\mathrm{dpp}^{0 /-}$ \\
& +0.75 & $\mathrm{PTZ}^{0 / 1+}$ \\
& +1.20 & $\mathrm{Ru}^{2+/ 3+\mathrm{b}}$ \\
& +1.36 & $\mathrm{PTZ}^{1+/ 2+}$ \\
\hline
\end{tabular}

${ }^{a} \mathrm{E}^{\mathrm{or}}$ values are obtained from $\mathrm{CV}$ traces and reported vs. $\mathrm{Ag} / \mathrm{AgCl}$ in $\mathrm{CH}_{3} \mathrm{CN}$ using $0.1 \mathrm{M}$ $\mathrm{TBAPF}_{6}{ }^{\mathrm{a}}$ anhydrous DMF. ${ }^{\mathrm{b}}$ Irreversible couple representing decomposition.

\section{Electronic Absorption and Emission}

The absorbance and emission spectra of complexes $\mathbf{2}$ and $\mathbf{3}$ are shown in Figure 2, with a summary of the electronic transitions and emission properties for the free PTZEtv ${ }_{2}$ bpy ligand, $\mathbf{1}$, $\mathbf{2}$ and $\mathbf{3}$ displayed in Table 2. Both complexes feature high energy ligand centered transitions and low energy Metal-to-Ligand Charge Transfer (MLCT) transitions in the visible region of the spectrum. However, these complexes exhibit slightly more intense CT bands than similar complexes. For example, complex 2 and $\mathbf{3}$ feature molar absorption coefficients of $\sim 50 \times 10^{-3}$ $\mathrm{M}^{-1} \mathrm{~cm}^{-1}$ for the MLCT transition as compared to $\sim 29 \times 10^{-3} \mathrm{M}^{-1} \mathrm{~cm}^{-1}$ for homoleptic tris $(4,7-$ diphenyl-1,10-phenanthroline)ruthenium(II) $\left(\left[\mathrm{Ru}\left(\mathrm{Ph}_{2} \mathrm{phen}\right)_{3}\right]^{2+}\right)$. Also, the fwhm (full-width at half maximum) for $\mathbf{2}$ and $\mathbf{3}$ is $\sim 9000 \mathrm{~cm}^{-1}$ and $\sim 10,000 \mathrm{~cm}^{-1}$, respectively, as compared to 4300 $\mathrm{cm}^{-1}$ for $\left[\mathrm{Ru}\left(\mathrm{Ph}_{2} \text { phen }\right)_{3}\right]^{2+} .^{[21]} \mathrm{We}$ speculate that the increased the extinction coefficient and 
broader CT transitions are due to mixing of the vinyl group with the bipyridine as part of the MLCT absorption manifold. In addition, there may be contributions from direct $\mathrm{PTZ} \rightarrow \mathrm{Ph}_{2}$ phen charge transfer within this absorption manifold. The emission data are typical of Ligand-to-Metal Charge Transfer (LMCT; polypyridine to $\mathrm{Ru}^{\mathrm{III}}$ ) emission behavior and is expected for the $\left[\mathrm{Ru}\left(\mathrm{Ph}_{2} \mathrm{phen}\right)_{2}\right]^{2+}$ portion of the dyad. However, the presence of the bpy-PTZ ligand distorts the emission behavior of complex 2 (and 3 ) when compared to $\mathbf{1}$. Complex 1 exhibits an emission lifetime of $6400 \mathrm{~ns}$ and an emission maximum of $618 \mathrm{~nm}$. In comparison, complex 2 and $\mathbf{3}$ feature much shorter lifetimes of 139 and 129 ns, respectively, and emission maxima of 765 and $750 \mathrm{~nm}$, respectively.

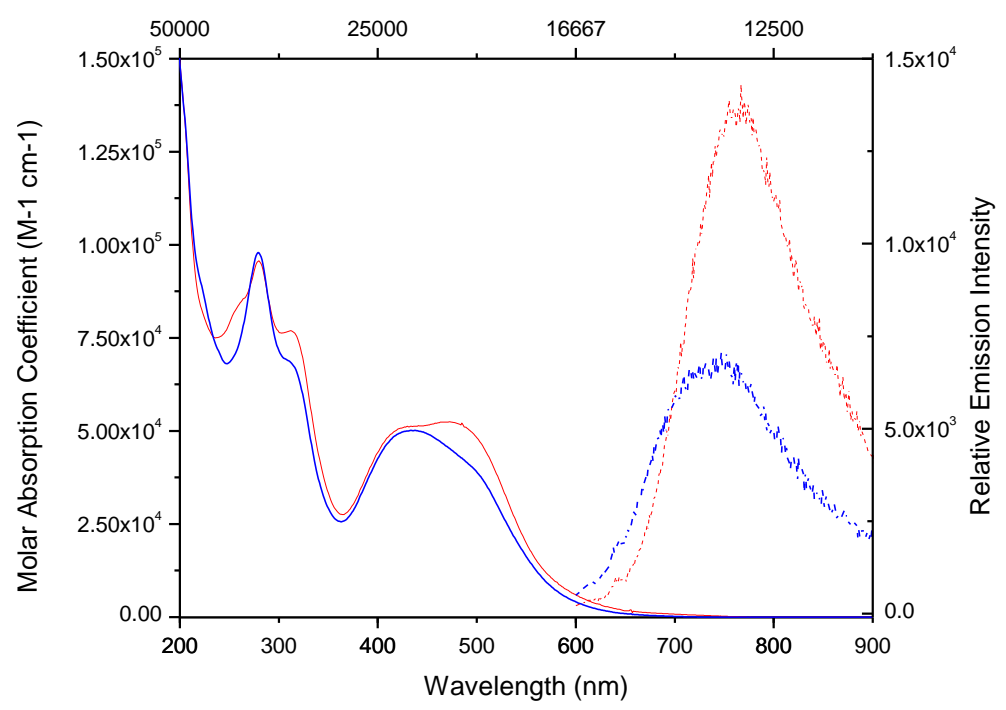

Figure 2. The optical absorption (solid line) and emission spectra (dotted line) of $\mathbf{2}$ (red) and $\mathbf{3}$ (blue).

Table 2. Absorption and Emission Data of Free Ligand, 1, 2, and 3.

\begin{tabular}{|c|c|c|c|c|c|}
\hline \multirow[b]{2}{*}{ Ligand/Complex } & \multicolumn{4}{|c|}{ Absorption } & Emission \\
\hline & $\begin{array}{c}\lambda_{\max }{ }^{\text {abs. }} \\
(\mathrm{nm})\end{array}$ & $\begin{array}{c}\varepsilon \times 10^{3} \\
\left(\mathrm{M}^{-1} \mathrm{~cm}^{-1}\right)\end{array}$ & $\begin{array}{c}\lambda_{\max .}{ }^{\mathrm{em} .} \\
(\mathrm{nm})\end{array}$ & $\begin{array}{l}\Phi^{\mathrm{em} .} \\
\times 10^{-4}\end{array}$ & $\begin{array}{c}\tau(\mathrm{RT}) \\
(\mathrm{ns})\end{array}$ \\
\hline PTZEtv $_{2}$ bpy & $\begin{array}{l}253 \\
305 \\
396\end{array}$ & - & 561 & ${ }^{b_{5}} 5260$ & - \\
\hline $\mathbf{1}^{\mathrm{a}}$ & 463 & 28.6 & 618 & 3660 & 6400 \\
\hline 2 & $\begin{array}{l}279 \\
311 \\
439\end{array}$ & $\begin{array}{l}97.9 \\
68.7 \\
50.1\end{array}$ & 765 & 12.91 & 139 \\
\hline
\end{tabular}




\begin{tabular}{|l|l|l|l|l|l|}
\hline \multirow{3}{*}{3} & 281 & 95.4 & & & \\
& 311 & 76.9 & & & \\
& 441 & 51.4 & 750 & 7.26 & \\
\hline
\end{tabular}

${ }^{a}$ Montalti, Marco, et al. Handbook of photochemistry. CRC press, 2006. (MeOH/EtOH). ${ }^{\mathrm{b}}$ 9,10-diphenylanthracene $\left(\Phi_{\mathrm{fl}}=0.97\right)$ as the reference standard.

\section{Nanosecond Transient Absorption}

Nanosecond transient absorption spectroscopy was employed to reveal whether or not the phenothiazine moiety would reductively quench the $\left[\mathrm{Ru}\left(\mathrm{Ph}_{2} \text { phen }\right)_{2}\right]^{2+}$ unit, facilitated by the presence of the double bond linker between the donor-acceptor pair. Similar dyads comprising an aliphatic or saturated linker between a ruthenium polypyridine center and PTZ do not feature effective electron transfer between the donor-acceptor pair, even though it is thermodynamically favorable. ${ }^{[1,2]}$ Nanosecond transient absorption spectra and the ground state electronic absorption spectrum of 2 are shown in Figure 3. Table 3 displays a summary of the results from kinetic fitting of these spectra. The 20 nanosecond transient features a negative absorption or bleach feature ranging from 400 to $\sim 550 \mathrm{~nm}$, whereas excited state absorption features appear at $\lambda<$ $400 \mathrm{~nm}$ and $\lambda>550 \mathrm{~nm}$. The excited state absorptions are typical of reduced polypyridine ligands (e.g., bpy or phen). The lowest energy excited state absorption is attributed to both unreduced polypyridine ligand to $\mathrm{Ru}^{3+} \mathrm{LMCT}$, and $\pi^{*} \rightarrow \pi^{*}$ transitions for the reduced polypyridine ligand. In aggregate, these features are representative of a MLCT excited state. At this time resolution, we are unable to observe the formation of this MLCT state.

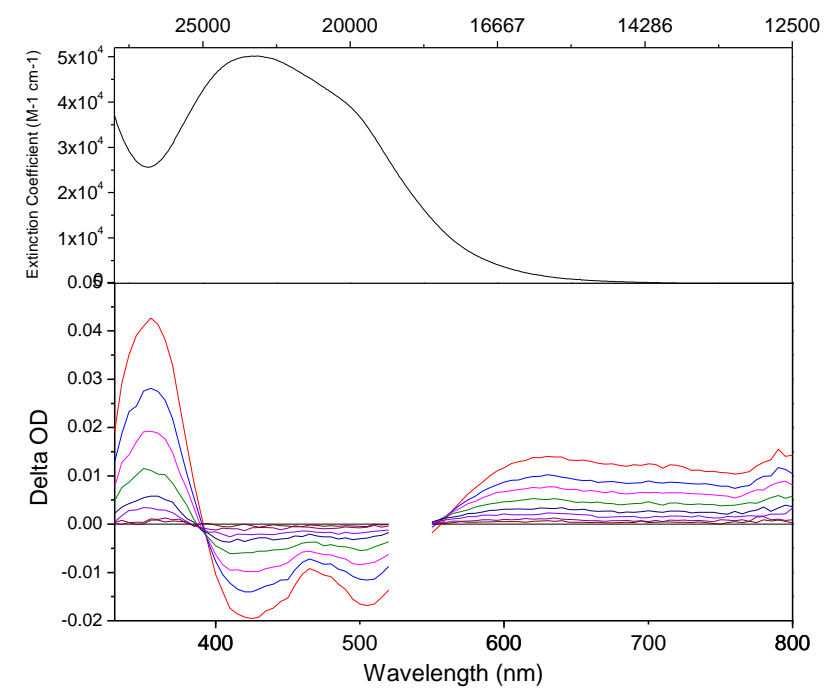

Figure 3. Top: Electronic absorption spectrum of 2. Bottom: Nanosecond transient absorption spectra of complex 2 obtained at different time delays excited at 532nm. Data near the excitation line have been removed for clarity. 
As stated above, the transient absorption signal is a composite of excited state absorptions and ground state negative peaks. The broad bleach feature actually appears as two negative peaks. In this case, we suspect that the appearance of two negative peaks in the transient absorption signal is the superposition of the excited state absorption of triplet phenothiazine ( ${ }^{3}$ PTZ), which often appears near $470 \mathrm{~nm},{ }^{[22]}$ and the ground state bleach with oxidized $\mathrm{Ru}^{\mathrm{III}}$ associated with the MLCT excited state. This feature is not likely due to oxidized phenothiazine $\left(\mathrm{PTZ}^{+} \bullet\right)$ as that typically appears near $510 \mathrm{~nm} .^{[22]}$ Indeed, nanosecond transient absorption spectra of $\left[\mathrm{Ru}\left(\mathrm{Ph}_{2} \text { bpy }\right)_{3}\right]^{2+}$, where $\mathrm{Ph}_{2}$ bpy is $4,4^{\prime}$-diphenyl-2,2'-bipyridine, show only a single broad bleach in this region of the spectrum. ${ }^{[23]}$ In our spectra, the maximum between these two negative peaks appears near $465 \mathrm{~nm}$. The presence of the vinyl group on the phenothiazine is expected to shift this absorption energy. Lastly, in the absence of an excited state absorption superposed on the MLCT bleach, there is no reasonable explanation for two negative peaks in the 20 nanosecond transient absorption spectrum.

These data suggest the presence of both ${ }^{3} \mathrm{PTZ}$ and ${ }^{3} \mathrm{MLCT} \mathrm{Ru}$, and that these excited states relax to the ground state starting material on the nanosecond timescale. The time constants for these two processes are different. The ${ }^{3}$ MLCT state relaxes to the singlet Ru ground state with a time constant of $\sim 130 \mathrm{~ns}$, consistent with the emission data of $\sim 140 \mathrm{~ns}$. The ${ }^{3} \mathrm{PTZ}$ relaxes to singlet PTZ ground state with a time constant of $\sim 300$ ns. Similarly, complex 3 features two lifetimes of 88 and $215 \mathrm{~ns}$ (Figures S14). The first lifetime corresponds to the ${ }^{3} \mathrm{MLCT} \mathrm{Ru}$ emission excited state lifetime (129 ns; Table 2 ) and the second time constant is ascribed to ${ }^{3}$ PTZ relaxation. These data suggest that there is no evidence for formation of the charge-separated state.

Table 3. Results from fits of single wavelength kinetics.

\begin{tabular}{|c|c|c|c|}
\hline \multirow{2}{*}{ Complex } & \multicolumn{3}{|c|}{ Delta OD } \\
\cline { 2 - 4 } & $\lambda_{\text {obs }}(\mathrm{nm})$ & $\tau_{1}(\mathrm{~ns})$ & $\tau_{2}(\mathrm{~ns})$ \\
\hline \multirow{4}{*}{2} & 355 & $125 \pm 1.5(92 \%)$ & $326 \pm 24.6(8 \%)$ \\
& 425 & $123 \pm 2.0(78 \%)$ & $306 \pm 11.0(22 \%)$ \\
& 465 & $140 \pm 2.7(68 \%)$ & $362 \pm 10.3(32 \%)$ \\
& 505 & $120 \pm 1.9(73 \%)$ & $292 \pm 8.0(27 \%)$ \\
$\mathbf{3}$ & 630 & $120 \pm 2.0(59 \%)$ & $303 \pm 4.4(41 \%)$ \\
\hline & 355 & $95 \pm 5.0(78 \%)$ & $206 \pm 21(22 \%)$ \\
& 410 & $93 \pm 1.2(91 \%)$ & $426 \pm 28(9 \%)$ \\
& 445 & $94 \pm 3.7(79 \%)$ & $265 \pm 20(21 \%)$ \\
& 500 & $79 \pm 1.3(78 \%)$ & $216 \pm 6(22 \%)$ \\
& 620 & $84 \pm 0.8(87 \%)$ & $289 \pm 7(13 \%)$ \\
\hline
\end{tabular}

\section{Conclusion}


Two new heteroleptic $\mathrm{Ru}(\mathrm{II})$ complexes containing phenothiazine functionalized bipyridines are reported with their spectral, electrochemical and photophysical properties. Specifically, excitation of these dyads readily creates ligand localized ${ }^{3} \mathrm{PTZ}$ and ${ }^{3} \mathrm{MLCT} \mathrm{Ru}$ on the sub-picosecond timescale. Nanosecond transient absorption data reveal relaxation of 3PTZ on $\sim 300 \mathrm{~ns}$ timescale and ground state recovery of the 3MLCT Ru state in $\sim 130 \mathrm{~ns}$. Additional studies are required to reveal the details of the formation of these two states.

\section{Acknowledgements}

Significant portions of this work were performed at Virginia Tech by GKK and TRC in Professor Karen Brewer's laboratory. Acknowledgement is made to the Chemical Sciences, Geosciences and Biosciences Division, Office of Basic Energy Sciences, Office of Sciences, U.S. Department of Energy DE FG02-05ER15751 (KJB) and Virginia Tech Institute for Critical Technology and Applied Science (ICTAS) for the generous financial support for our research. This material is also based upon work supported by the National Science Foundation under Grant CHE 1112250 (JJR).

\section{References}

1. Hanss, D. and O.S. Wenger, Tunneling Barrier Effects on Photoinduced Charge Transfer through Covalent Rigid Rod-Like Bridges. Inorganic Chemistry, 2009. 48(2): p. 671-680.

2. He, B. and O.S. Wenger, Ruthenium-Phenothiazine Electron Transfer Dyad with a Photoswitchable Dithienylethene Bridge: Flash-Quench Studies with Methylviologen. Inorganic Chemistry, 2012. 51(7): p. 4335-4342.

3. Larson, S.L., C.M. Elliott, and D.F. Kelley, Electron Transfer in Phenothiazine/Ru(bpy)32+ Donor-Chromophore Complexes. Inorganic Chemistry, 1996. 35(7): p. 2070-2076.

4. Chandrasekharam, M., et al., Phenothiazine conjugated bipyridine as ancillary ligand in Ru(II)complexes for application in dye sensitized solar cell. Synthetic Metals, 2011. 161(15-16): p. 1469-1476.

5. Maxwell, K.A., et al., One-Pot Synthesis and Characterization of a Chromophore-Donor-Acceptor Assembly. Inorganic Chemistry, 2000. 39(1): p. 71-75.

6. Chakraborty, S., et al., Platinum Chromophore-Based Systems for Photoinduced Charge Separation: A Molecular Design Approach for Artificial Photosynthesis. Inorganic Chemistry, 2005. 44(20): p. 6865-6878.

7. Danielson, E., et al., Photochemically induced charge separation at the molecular level. A chromophore-quencher complex containing both an electron donor and an acceptor. Journal of the American Chemical Society, 1987. 109(8): p. 2519-2520.

8. Weber, J.M., et al., High Energy and Quantum Efficiency in Photoinduced Charge Separation. Journal of the American Chemical Society, 2007. 129(2): p. 313-320. 
9. Ajayakumar, G., et al., Light-induced charge separation and photocatalytic hydrogen evolution from water using RullPtII-based molecular devices: Effects of introducing additional donor and/or acceptor sites. Dalton Transactions, 2011. 40(15): p. 3955-3966.

10. She, Z., et al., Novel Ruthenium Sensitizers with a Phenothiazine Conjugated Bipyridyl Ligand for High-Efficiency Dye-Sensitized Solar Cells. ACS Applied Materials \& Interfaces, 2015. 7(50): p. 27831-27837.

11. Kumaresan, D., K. Lebkowsky, and R.H. Schmehl, Photoinduced charge separation and recombination in solution and in gels of a Pt(II) terpyridyl-naphthalene diimide complex. Journal of Photochemistry and Photobiology A: Chemistry, 2009. 207(1): p. 86-93.

12. Manbeck, G.F. and K.J. Brewer, Photoinitiated electron collection in polyazine chromophores coupled to water reduction catalysts for solar $\mathrm{H}-2$ production. Coordination Chemistry Reviews, 2013. 257(9-10): p. 1660-1675.

13. White, T.A., et al., Efficient Photocatalytic Hydrogen Production in a Single-Component System Using Ru,Rh, Ru Supramolecules Containing 4,7-Diphenyl-1,10-Phenanthroline. Angewandte Chemie International Edition, 2011. 50(51): p. 12209-12213.

14. Arachchige, S.M. and K.J. Brewer, A donor-chromophore complex containing the polyazine bridging ligand 2,3-bis(2-pyridyl)pyrazine. Inorganic Chemistry Communications, 2007. 10(10): p. 1159-1163.

15. Mongelli, M.T. and K.J. Brewer, Synthesis and study of the light absorbing, redox and photophysical properties of Ru(II) and Os(II) complexes of 4,7-diphenyl-1,10-phenanthroline containing the polyazine bridging ligand 2,3-bis(2-pyridyl)pyrazine. Inorganic Chemistry Communications, 2006. 9(9): p. 877-881.

16. Ashford, D.L., et al., Molecular Chromophore-Catalyst Assemblies for Solar Fuel Applications. Chemical Reviews, 2015. 115(23): p. 13006-13049.

17. Grusenmeyer, T.A., et al., $\mathrm{pH}$ Control of Intramolecular Energy Transfer and Oxygen Quenching in Ru(II) Complexes Having Coupled Electronic Excited States. Journal of the American Chemical Society, 2012. 134(17): p. 7497-7506.

18. Castellano, F.N., Altering Molecular Photophysics by Merging Organic and Inorganic Chromophores. Accounts of Chemical Research, 2015. 48(3): p. 828-839.

19. Borgström, M., et al., Electron Donor-Acceptor Dyads and Triads Based on Tris(bipyridine)ruthenium(II) and Benzoquinone: Synthesis, Characterization, and Photoinduced Electron Transfer Reactions. Inorganic Chemistry, 2003. 42(17): p. 5173-5184.

20. Jang, S.-R., et al., Oligophenylenevinylene-Functionalized Ru(II)-bipyridine Sensitizers for Efficient Dye-Sensitized Nanocrystalline TiO2 Solar Cells. Chemistry of Materials, 2006. 18(23): p. 56045608.

21. $\quad$ Barton, J.K., et al., Chiral probes for the handedness of DNA helices: enantiomers of tris(4,7diphenylphenanthroline)ruthenium(II). Proceedings of the National Academy of Sciences, 1984. 81(7): p. 1961-1965.

22. Barra, M., et al., Photophysical and photochemical studies of phenothiazine and some derivatives: exploratory studies of novel photosensitizers for photoresist technology. Chemistry of Materials, 1991. 3(4): p. 610-616.

23. Damrauer, N.H. and J.K. McCusker, Ultrafast Dynamics in the Metal-to-Ligand Charge Transfer Excited-State Evolution of [Ru(4,4'-diphenyl-2,2'-bipyridine)3]2+. The Journal of Physical Chemistry A, 1999. 103(42): p. 8440-8446. 
Graphical Abstract (Pictogram)

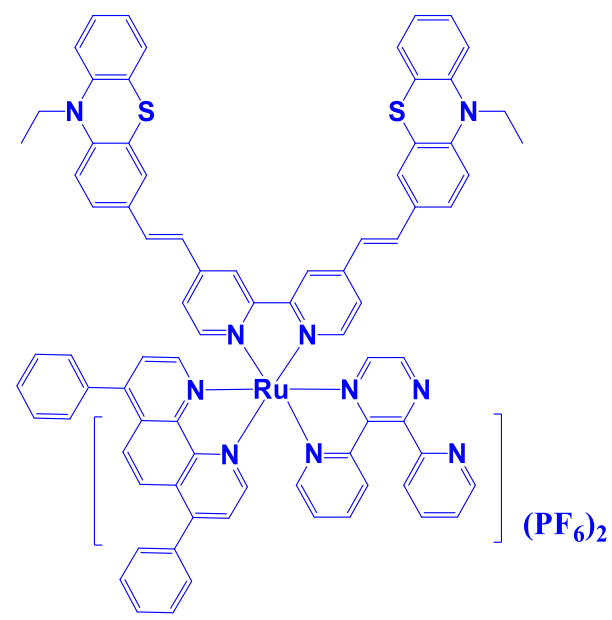


A bipyridine phenothiazine ligand $\left[\left(\mathrm{PTZEtv}_{2} \mathrm{bpy}\right)\right.$ and metal complexes $\left[\mathrm{Ru}\left(\mathrm{Ph}_{2} \mathrm{phen}\right)_{3}\right]^{2+}(\mathbf{1})$, $\left[\left(\mathrm{Ph}_{2} \text { phen }\right)_{2} \mathrm{Ru}\left(\mathrm{PTZEtv}{ }_{2} \text { bpy }\right)\right]^{2+} \quad$ (2), and $\left[\left(\mathrm{PTZEtv}{ }_{2} \text { bpy }\right)\left(\mathrm{Ph}_{2} \text { phen }\right) \mathrm{Ru}(\mathrm{dpp})\right]^{2+} \quad$ (3) were synthesized and characterized, where $\mathrm{Ph}_{2}$ phen is 4,7-diphenyl-1,10-phenanthroline, dpp is 2,3bis(2-pyridyl)pyrazine and PTZEtv 2 bpy is 4,4' ethylene bridged phenothiazine 2,2'bipyridine. The reduction potentials of PTZEtv 2 bpy, 1, 2, and $\mathbf{3}$ were determined by cyclic and square wave voltammetric methods. The absorbance and emission spectra of complexes $\mathbf{2}$ and $\mathbf{3}$ yield intense, visible Metal-to-Ligand Charge Transfer (MLCT) transitions. The nanosecond transient absorption data indicate formation of both the ${ }^{3}$ MLCT state and a ligand localized ${ }^{3} \mathrm{PTZ}$ state. 